\title{
Well-Being without Being? A Reply to Feit
}

\author{
ERIK CARLSON AND JENS JOHANSSON \\ Uppsala University
}

In a recent Utilitas article, Neil Feit argues that every person occupies a well-being level of zero at all times and possible worlds at which she fails to exist. Views like his face the 'problem of the subject': how can someone have a well-being level in a scenario where she lacks intrinsic properties? Feit argues that this problem can be solved by noting, among other things, that a proposition about a person can be true at a possible world in which neither she nor the proposition exists. In this response, we argue that Feit has not solved the problem of the subject, and also raise various related problems for his approach.

\section{INTRODUCTION}

It is clear that a person who currently exists occupies a well-being level (positive, negative, or neutral). Will she still occupy a well-being level when she no longer exists? And would she have done so even if she had never existed at all? In a recent Utilitas article, Neil Feit defends an affirmative answer to both of these questions. ${ }^{1}$ According to Feit, any person has a neutral well-being level - a well-being level of zero - at any time and possible world at which she does not exist. This view, Feit argues, has the virtue of ruling out the unattractive view that a person's death can at most be an atemporal harm for her, and of supporting the attractive view that coming into existence harms those whose lives are miserable.

As Feit notes, views like his are often alleged to be vulnerable to the 'problem of the subject'. The idea is roughly that having a well-being level in a scenario requires having intrinsic properties there, which in turn requires existing there. However, Feit argues that we can solve the problem of the subject by noting that a proposition about a person - e.g. that she has a well-being level of zero - can be true at a time and world, even if the person, or indeed the proposition itself, does not exist at that time and world.

In this response, we shall argue that Feit has not solved the problem of the subject, and also raise various related problems for his approach.

${ }^{1}$ Neil Feit, 'Comparative Harm, Creation and Death', Utilitas 28 (2016), pp. 136-63.

(c) Cambridge University Press 2017. This is an Open Access article, distributed under the terms of the Creative Commons Attribution licence (http://creativecommons.org/ licenses/by/3.0/), which permits unrestricted re-use, distribution, and reproduction in any medium, provided the original work is properly cited. Utilitas Vol. 30, No. 2, June 2018

doi:10.1017/S0953820817000103 


\section{FEIT'S APPROACH}

Feit claims, against the Epicurean position to the contrary, that death can be a bad thing for the person who dies. He bases this claim on the counterfactual comparative account of an event's value for a person, which he formulates as follows:

The Comparative Account (Ordinary Language Version): The value of event $\mathrm{E}$ for person $\mathrm{S}$ is the difference between the amount of well-being for $\mathrm{S}$ (given that $\mathrm{E}$ occurs) and the amount of well-being that $\mathrm{S}$ would have received had $\mathrm{E}$ not occurred. ${ }^{2}$

Or, in terms of possible worlds:

The Comparative Account (Possible Worlds Version): The value of event $\mathrm{E}$ for person $\mathrm{S}=$ the amount of well-being for $\mathrm{S}$ minus the amount of well-being for $\mathrm{S}$ at the nearest possible world where $\mathrm{E}$ does not occur. ${ }^{3}$

Because, in many cases, the subject would have received a greater amount of well-being had her death not occurred, the Comparative Account yields that death, in many cases, is bad for the one who dies. Feit holds, moreover, that an event harms a person if and only if it is bad for her, in which case we can also conclude that death, in many cases, harms the one who dies.

According to Feit, however, our account of death's badness is not complete until we have also specified when death is bad for the one who dies. Like many others, Feit understands talk of the timing of an event's value in the following way:

Comparative Value at a Time: The value of event $\mathrm{E}$ for person $\mathrm{S}$ at time $t=$ S's well-being level at $t$ minus S's well-being level at $t$ at the nearest possible world where $\mathrm{E}$ does not occur. ${ }^{4}$

Feit defends 'subsequentism', the view that death is bad for its victim after it occurs. If Michael Jackson's death is bad for him, for instance, there are times after his death at which he would have occupied a positive well-being level if it had not occurred. Moreover, Feit claims, Jackson's actual well-being level at those times is zero. Consequently, Jackson's death is bad for him at those times.

The idea behind Feit's claim that Jackson has a well-being level of zero after his death is not that Jackson exists - is located or present - at those times. Feit accepts, for the sake of argument, that death is the end of an individual's existence. (We shall make this assumption as well.) Instead, Feit contends that it holds quite generally that being

2 Feit, 'Comparative Harm, Creation and Death', p. 139.

${ }^{3}$ Feit, 'Comparative Harm, Creation and Death', p. 139.

4 Feit, 'Comparative Harm, Creation and Death', p. 140. 
absent from a situation implies having a well-being level of zero there, or more precisely:

Outer Zero View: For any person S, any time $t$, and any world $w$, if $t$ is a time at which $\mathrm{S}$ is not located in $w$, then S's well-being level at $t$, at $w$, is zero. ${ }^{5}$

Feit stresses that the Outer Zero View can be used to support not only subsequentism about the badness of death, but also the thesis that coming into existence can be bad for a person who lives an overall miserable life. By the Outer Zero View, at the nearest possible world in which such a person - Nora, say - does not come into existence, her well-being level is zero at every time. Plausibly, this is enough for the amount of well-being for her at that world to be zero. By the Comparative Account, then, it is bad for Nora to come into existence.

How, then, can the Outer Zero View be true; in particular, what is Feit's response to the 'problem of the subject'? He takes this problem primarily to consist in the following two claims:

(PS1) A person has a well-being level at time $t$ only if she has intrinsic properties at $t$.

(PS2) A person has an intrinsic property at time $t$ only if she is located at $t^{6}$

As Feit notes, the 'intrinsic' qualification is needed since someone who has gone out of existence might well have extrinsic properties such as being eulogized or being forgotten.

Some might hold that PS2 is radically wrong since it is possible to have intrinsic properties at a time without ever existing. That is not Feit's strategy: he endorses 'Actualism', the doctrine that entities that never exist in a world never have any properties there (intrinsic or extrinsic). Nor does he follow Ben Bradley in denying PS2 on the grounds that someone who no longer exists at a time can have intrinsic properties then, such as being round or not round. ${ }^{7}$ According to Feit, it is more plausible to deny PS1. He does not deny that there are properties such as having some well-being level and having a wellbeing level of zero, or that those properties are sometimes exemplified. Moreover, he does not deny that having such a property at a time and world requires having intrinsic properties at that time and world (whether or not the property is itself intrinsic). But, he suggests, having a well-being level of zero at a time and world does not require having any intrinsic properties at that time and world - not even those required

${ }^{5}$ Feit, 'Comparative Harm, Creation and Death', p. 159. As we shall see, this 'outer' view should be distinguished from its 'inner' relative.

${ }^{6}$ Feit, 'Comparative Harm, Creation and Death', p. 146.

7 Ben Bradley, Well-Being and Death (Oxford, 2009), p. 107. 
for having the property of having a well-being level of zero. (Having that property itself is hence not necessary for having a well-being level of zero.)

In support of this suggestion - and of his overall position - Feit points out that in the case of a person who exists at time $t$ - Greg, say - there are two ways for him to have a well-being level of zero at $t$. Assuming hedonism for purposes of illustration, the first way is for the experiences of pleasure and pain that Greg receives at $t$ to exactly balance out one another. The second way is for Greg not to receive any pleasure or pain at all at $t$ - that is, 'the propositions that it is not the case that Greg is pleased at $t$, and that it is not the case that Greg is in pain at $t$, together entail that Greg's well-being level at $t$ is zero'. ${ }^{8}$ Clearly, the first of these two ways is not applicable to an individual who, unlike Greg, does not exist at $t$. But, Feit maintains, the second way is. For example, if $t$ is a time after Michael Jackson's death, the propositions that it is not the case that Jackson is pleased at $t$, and that it is not the case that Jackson is in pain at $t$, are both true, even though Jackson does not have any intrinsic properties at $t$. As in Greg's case, moreover, they jointly entail that Jackson's well-being level at $t$ is zero. Hence, that Jackson's well-being level at $t$ is zero is itself true. Similarly, for any time $t$ in a world where Nora never exists, the propositions that it is not the case that Nora is pleased at $t$, and that it is not the case that Nora is in pain at $t$, are both true at that world, even though Nora has no properties there. As in Greg's case, moreover, they jointly entail that Nora's well-being level at $t$ is zero. Hence, that Nora's well-being level at $t$ is zero is itself true at that world.

To see more clearly how this approach solves the problem of the subject, Feit says, we need to take note of an important distinction, due to Kit Fine:

The idea is that there is an inner and an outer notion of truth for propositions. Relative to a given possible world, a proposition is true according to the outer notion provided that it represents the world correctly; the proposition need not exist in the world. On the other hand, a proposition is true according to the inner notion provided that it correctly represents and exists in the given world. ${ }^{9}$

Feit adopts the conventional terminology whereby a proposition is true $a t$ a given world just in case, relative to that world, the proposition is true according to the outer notion; and a proposition is true in a given world just in case, relative to that world, the proposition is true according to the inner notion. Following Fine, Feit denies that

8 Feit, 'Comparative Harm, Creation and Death', p. 155.

9 Feit, 'Comparative Harm, Creation and Death', p. 156. 
propositions like that it is not the case that Nora is pleased at $t$, that it is not the case that Nora is in pain at $t$, and that Nora's well-being level at $t$ is zero, exist in a world where Nora does not exist. Consequently, we should reject the following view (where for S's well-being level to be $n$ in a possible world is for the proposition that $S$ 's well-being level is $n$ to be true in that world):

Inner Zero View: For any person $\mathrm{S}$, any time $t$, and any world $w$, if $t$ is a time at which $\mathrm{S}$ is not located in $w$, then S's well-being level at $t$, in $w$, is zero. ${ }^{10}$

Crucially, however, the falsity of the Inner Zero View does not undermine the Outer Zero View, or the claim that the proposition that Nora's well-being level is zero is true at - that is, correctly represents - every world in which Nora does not exist. Plausibly, moreover, outer truth is what is relevant to ordinary counterfactuals, and therefore to the Ordinary Language Version of the Comparative Account. So long as the proposition that Nora's well-being level is zero is true at the nearest possible world at which that Nora never exists is true, it is true that if Nora had never existed, then she would have had a well-being level of zero.

Feit makes sure to distance himself not only from the Inner Zero View, but also from another extreme view, which might easily be associated with his:

I want to stress that I am not arguing that individuals can be harmed by failing to exist or by being prevented from existing. The Loch Ness monster and Barack Obama's (merely possible) third child have not been harmed. This follows from my commitment to Actualism. Only actually existing individuals can be harmed or benefited. ${ }^{11}$

Thus, while various events - including coming into existence, and going out of it - can harm those who exist at some point, nothing - including never coming into existence - can harm never existing individuals.

\section{CRITIQUE OF FEIT}

The first thing to note is that the distinction between inner and outer truth is less relevant to the problem of the subject than Feit suggests. Admittedly, the distinction allays the following potential worry: it cannot be true that Nora would have a well-being level of zero if she had never existed, because the proposition that Nora has a well-being level of zero would not exist, let alone be true, if Nora had never existed. But allaying this worry is hardly a way of allaying the main worries

${ }^{10}$ Feit, 'Comparative Harm, Creation and Death', p. 159.

11 Feit, 'Comparative Harm, Creation and Death', p. 155. 
of those who are drawn to PS1 and PS2. Presumably, for instance, one common and natural idea behind PS1 - the claim that a person has a well-being level at $t$ only if she has intrinsic properties at $t$ - is that a person cannot have a well-being level at $t$ unless she has, at $t$, some sort of capacity for mental states (something that arguably requires having intrinsic properties at $t$ ). This idea is by no means countered by the inner/outer distinction. ${ }^{12}$ Indeed, the idea is fully compatible with the popular view that the existence of a singular proposition does not presuppose the existence of the individual it is about - and thus with saying that the existence of the proposition that Nora has a well-being level of zero does not presuppose the existence of Nora. In particular, maybe the proposition exists, but is false, in every world where Nora does not exist.

Relatedly, Feit has not provided very much by way of positive support for his view. As we saw, he claims that in the case of Greg, who exists at $t$ (and assuming hedonism), (a) that it is not the case that Greg is pleased at $t$, and (b) that it is not the case that Greg is in pain at $t$, jointly entail (c) that Greg's well-being level at $t$ is zero - and that the corresponding entailment therefore holds in the case of an individual who no longer exists at $t$, or never exists in a given possible world. But it is not clear why we should accept, even in Greg's case, that the entailment holds. It may well be that (a), (b), and (d) that Greg exists at $t$, jointly entail (c). However, this does not show that (a) and (b) jointly entail (c), even given the truth of (d). After all, whether existence at a time and world is needed for having a well-being level at that time and world is precisely what is at issue. ${ }^{13}$

It would help Feit's argument if there were plenty of other scales for which the analogous entailment holds, that is, scales where the absence of the relevant positive and negative properties suffices for occupying a zero level. Most scales, however, are not like this - not even if we concentrate on those that (like the well-being scale) apparently have a non-arbitrary zero point, and allow for both positive and negative levels. Consider wealth and physical attractiveness, for instance. Michael Jackson does not currently have any positive or negative wealth, but he does not thereby currently have zero wealth: that would imply, implausibly, that Jackson is much poorer now than when he was alive, and that he is now poorer than most people in the US, but richer

\footnotetext{
12 This does not mean, of course, that this idea is without problems; for example, Feit criticizes it on pp. $144-5$.

${ }^{13}$ Krister Bykvist makes a related point in response to one of Nils Holtug's arguments; see 'The Benefits of Coming into Existence', Philosophical Studies 135 (2007), pp. 332-62, at 343. Unlike Bykvist's response to Holtug, however, our criticism of Feit's argument is not that it violates Actualism.
} 
than some. Similarly, Jackson is not currently physically attractive or unattractive (unlike, perhaps, his corpse - remember the assumption that everyone ceases to exist at death), but he does not thereby occupy a zero level of physical attractiveness. Admittedly, there may well be some scales that in some respects come close to behaving in the pertinent way. Arguably, for example, even a person who has gone out of existence currently occupies a zero level of popularity - and, indeed, currently exemplifies the property of occupying a zero level of popularity - if she is not currently an object of any positive or negative attitudes. However, we doubt whether there is any scale $\mathrm{s}$ - other than the well-being scale, if Feit is right - which is both such that exemplification of the property of having an s-level of zero at a time and world requires having intrinsic properties at that time and world, and such that a person can have an $s$-level of zero, rather than no $s$ level, after she has ceased to exist (and thus, as Feit grants, ceased to have any intrinsic properties). For instance, the wealth and physical attractiveness scales seem to satisfy the first condition, but not the second; the popularity scale seems to satisfy the second condition, but not the first. Furthermore, in our view there is no clear example of a scale such that a person would have occupied a level of zero on it, rather than no level on it, if she had never existed. The popularity scale is certainly not such an example; if Nora had never existed, she would not have been more or less popular than anyone. While these considerations do not rule out that the well-being scale is simply different from other scales in these regards, they do put additional pressure on Feit's move from (a) and (b) to (c).

An apparent implication of Feit's line of reasoning, moreover, is that inanimate objects, such as shoes, have a well-being level of zero at all times. After all, a shoe never experiences any pleasure or pain. Thus, if Donald Trump's current well-being level is positive, it is higher than that of his left shoe. Feit concedes that such claims 'might intuitively seem false', but thinks that accepting their truth 'is at most a small cost'. ${ }^{14}$ For those unwilling to pay this cost, however, he suggests the requirement that one possibly has positive or negative well-being at some time, for one to have a well-being level of zero at a time and world. This presumably precludes Trump's shoe from having zero well-being at any time.

This solution comes with another cost, however ${ }^{15}$ A hedonist should say that one's current well-being level is wholly determined by the

14 Feit, 'Comparative Harm, Creation and Death', p. 160.

15 Jens Johansson, 'The Timing Problem', The Oxford Handbook of Philosophy of Death, ed. Ben Bradley, Fred Feldman, and Jens Johansson (New York, 2013), pp. 255-73, at 265 . 
intrinsic properties of one's current mental states. Michael Jackson, who no longer exists, has the same current mental states as Trump's shoe, that is, none at all. Hence, Jackson and the shoe cannot differ as regards current well-being. Given the proposed requirement, however, Jackson's current well-being level is zero, whereas Trump's shoe has no well-being level. If anything, the reverse would be less surprising, as the shoe is at least still with us.

Feit responds that the hedonist can still claim (where, as we understand it, well-being properties are properties such as having $a$ well-being level of $n$ )

that one's well-being properties are determined by the intrinsic properties of one's mental states. . . . This view implies that Jackson and the shoe are now alike with respect to their well-being properties, which seems to be a good enough response $\ldots{ }^{16}$

We do not find this response good enough. It is true that Feit's proposal allows the hedonist to maintain that one's well-being properties at $t$ are wholly determined by the intrinsic properties of one's mental states at $t$. But if allowing this appears to help, that is only because it is naturally taken to imply that the hedonist is allowed to maintain that one's well-being level at $t$ is wholly determined by the intrinsic properties of one's mental states at $t$. This implication, of course, is precisely what Feit's proposal blocks. Indeed, saying that Jackson and the shoe differ with regard to having a well-being level of zero but not with regard to having the property of having a well-being level of zero, seems more implausible than saying that whereas Jackson has both the well-being level and the property, the shoe lacks both.

A further difficulty emerges when we consider non-hedonistic theories of well-being (with which Feit should, and apparently does, want his account to be compatible). On an objective list theory, certain wellbeing components, such as friendship and knowledge, may be necessary to have a non-negative well-being level. It does not seem unreasonable to say, of a person who has no friends, no knowledge, and so forth, that her well-being level is negative. ${ }^{17}$ Now, the propositions that Nora has no friends and that Nora has no knowledge, for example, are true at all times at a world where Nora does not exist. So, if she has a wellbeing level there, as Feit claims, it would seem that she has a negative well-being level there, on the sketched objective list theory. This is an

16 Feit, 'Comparative Harm, Creation and Death', pp. 161-2.

17 An anonymous referee has objected that, on a plausible objective list theory, having negative well-being presupposes things like having enemies or false beliefs, rather than just lacking friends or knowledge. The underlying intuition seems to be that the mere absence of things contributing to a good life cannot make a life bad. We find this far from obvious. For example, many believe that a life spent entirely in a coma is a bad life. 
absurd conclusion. On a more reasonable interpretation of objective list theories, a person occupies a negative well-being level at a world only if she is in a state there in which she lacks friends, knowledge, etc. One cannot be in such a state without existing. But if Feit were to insist on this interpretation of objective list theories, he would be hard pressed to explain why hedonism should not be interpreted in a similar way. That is, why does having zero well-being at a world not presuppose being in a state there in which one experiences neither pleasure nor pain (or equal amounts of pleasure and pain)? If it does, someone who fails to exist in a world cannot have zero well-being there.

As we have seen (sect. II), Feit emphatically denies that an individual can be harmed or benefited by being prevented from existing. We, too, emphatically deny this claim. In fact, however, it is hard to see any reasonable way for Feit to avoid it. Consider a possible world w where an event E prevents Greg from existing. Suppose that it is true at $\mathrm{w}$ that had E not occurred, then Greg would have had a happy life. On Feit's view, Greg has a well-being level of zero at $w$. So, it is true at $w$ that he would have received a greater amount of well-being if $\mathrm{E}$ had not occurred. According to Feit's counterfactual comparative account of harm (sect. II), an event harms a person just in case she receives a greater amount of well-being at the nearest possible world where the event does not occur. Surely if this account is true, then it is also true at $w$. At $w$, then, it is true that $\mathrm{E}$ harms Greg. ${ }^{18}$

This example involved a non-actual scenario where an event prevents an actual individual from existing. Consider also an actual scenario in which an event $E$ prevents a non-actual individual from existing. It can hardly be that whereas an actual individual has a well-being level of zero at worlds where she does not exist, a non-actual individual does not. Of course, Feit holds that if an individual S does not exist, then there are no singular propositions about $\mathrm{S}$, and so it is not the case that the singular proposition that S's well-being level is zero is true. Presumably, however, there are still suitable propositions of other sorts, such as that the individual who would have been born as a result of the non-occurrence of $E$ has a well-being level of zero. There seems to be no good reason to deny the existence of this proposition - in particular, it does not matter that there is no such thing as the individual who would have been born as a result of the non-occurrence of $\mathrm{E}$, as this is not a singular proposition about any such individual. Furthermore, the proposition appears to be true on Feit's view, since both that it is not the case that the individual who would have been born as a result

\footnotetext{
18 This is a problem for Feit's claim that Greg has a well-being level of zero at $w$, and not only for the combination of this claim and Feit's counterfactual comparative account of harm. In our view, the counterfactual comparative account of harm is plausible.
} 
of the non-occurrence of $E$ is pleased, and that it is not the case that the individual who would have been born as a result of the non-occurrence of $E$ is in pain, are true. Assuming that, if $E$ had not occurred, then it would have been the case that the individual who was born as a result of the non-occurrence of $\mathrm{E}$ has a positive well-being level, it is hard to see any plausible way for Feit to avoid the truth of that $E$ harms the individual who would have been born as a result of the non-occurrence of $E$.

As we saw (sect. II), Feit says that it follows from Actualism - the view that entities that never exist in a world never have any properties there - that only actually existing individuals can be harmed. However, Actualism by itself does not have this implication. An implicit premise in Feit's argument is that one can be harmed only if one exemplifies some property (perhaps the property of being harmed). Although this premise is plausible in itself, it looks like an ad hoc restriction in Feit's case. To begin with, making an individual occupy a lower well-being level than she would have otherwise done, by placing her at a well-being level of zero, really does seem sufficient for harming her. At least, it is not reasonable for a proponent of the counterfactual comparative account of harm to say that only some events that satisfy that condition harm the individual. Moreover, Feit must explain why being harmed presupposes having properties, although having zero well-being does not.

It could be suggested that an event harms an individual only if it makes her undergo intrinsic change, which in turn requires her to have properties. Whatever the merits of this proposal, however, it is incompatible with Feit's counterfactual comparative account of harm. Suppose that, unbeknownst to Greg, an eccentric billionaire decides to flip a coin about whether or not to give him a million dollars. If the coin lands heads, the billionaire will give Greg the money, otherwise she will do nothing. As it happens, the coin lands tails. Assuming that receiving the money would have increased Greg's well-being, the counterfactual comparative account implies that the event of the coin landing tails harms him. But this event does not make Greg undergo any intrinsic change.

Moreover, claiming that being harmed requires existence (whether or not for Actualist reasons), while having a well-being level of zero does not, has some implausible consequences. Suppose again that Nora has an unhappy life, and let $\mathrm{E}$ be the event of her conception. On Feit's view, E harms Nora. (We assume that she would not have existed if $\mathrm{E}$ had not occurred.) If an event harms a person, she would, at least typically, have been better off had this event not occurred. ${ }^{19}$ And sure

19 This is, of course, always the case according to the counterfactual comparative view of harm. On certain other views, there are exceptions. Cases of causal overdetermination or pre-emption are much-discussed cases in point. 
enough, if Nora's well-being level is zero at worlds where she does not exist, then she is better off at those worlds than at the actual world. So Feit's view implies that Nora would have been better off if $\mathrm{E}$ had not occurred. But if she would have been better off had E not occurred, it appears that she would have benefited from the non-occurrence of $\mathrm{E}$. (At least this is so if we assume that, from the perspective of the closest possible non-E-world, the closest E-world is the actual world, or some other world where Nora has an unhappy life.) This is not true on Feit's view, however, since being benefited at a world requires existing there. It is distinctly odd, we think, to claim that $\mathrm{E}$ harms Nora, and that she would have been better off if $\mathrm{E}$ had not occurred, but nevertheless deny that she would have benefited from the non-occurrence of $\mathrm{E}$.

Feit might retort that the non-occurrence of $\mathrm{E}$ is not an event, and that, on his view of harms and benefits, only events can benefit a person. To counter this reply, we may assume that if $\mathrm{E}$ had not occurred, this would have been due to some event $\mathrm{E}^{*}$, which would have prevented $\mathrm{E}$. In this case, Feit's view implies that $\mathrm{E}^{*}$ would have made Nora better off (assuming that, as seen from the closest $\mathrm{E}^{*}$-world, the closest non- $\mathrm{E}^{*}$ world is one in which Nora is unhappy). Since Nora does not exist in the closest $\mathrm{E}^{*}$-world, Feit is nonetheless bound to deny that $\mathrm{E}^{*}$ would have benefited her. Again, we find this lack of connection between benefiting and making better off quite implausible. ${ }^{20}$

erik.carlson@filosofi.uu.se

jens.johansson@filosofi.uu.se

${ }^{20}$ We are grateful to Dale Miller, two anonymous referees and participants in the research seminar in practical philosophy at Uppsala University for very helpful comments. Work for this article was supported by grant P14-0212:1 from Riksbankens Jubileumsfond. 